\title{
Identification of Antibacterial Activity with Bioactive Compounds from Selected Marine Sponges
}

\author{
Noor Azlina Kamaruding, Noraznawati Ismail*, Noormaizura Sokry
}

\section{Noor Azlina Kamaruding, Noraznawati Ismail*, Noormaizura Sokry}

Institute of Marine Biotechnology, Universiti Malaysia Terengganu, 21030 Kuala Nerus, Terengganu, MALAYSIA.

\section{Correspondence}

Assoc. Prof. Dr. Noraznawati Ismail

Institute of Marine Biotechnology, Universiti Malaysia Terengganu, 21030 Kuala Nerus, Terengganu, MALAYSIA. E-mail: noraznawati@umt.edu.my

History

- Submission Date: 16-02-2020;

- Review completed: 28-02-2020;

- Accepted Date: 16-03-2020.

DOI : 10.5530/pj.2020.12.76

Article Available online http://www.phcogj.com/v12/i3

Copyright

(C) 2020 Phcogj.Com. This is an openaccess article distributed under the terms of the Creative Commons Attribution 4.0 International license.

\begin{abstract}
Background: Marine sponges (phylum Porifera) are sessile filter-feeders from the ocean that are becoming the wealthiest sources of pharmacologically active compounds. Objectives: Our objectives are to identify bioactive compounds from marine sponges (Xestospongia exigua, Xestospongia muta, and lotrochota baculifera) and to determine their antibacterial activity. Materials and Methods: Methanolic crude extracts were subjected to two-steps fractionation: first, solvent partitioning was conducted using diethyl ether and butanol, followed by column chromatography. The resulting fractions were tested for antibacterial activity against four bacterial strains (Staphylococcus aureus ATCC 25923, Micrococcus luteus ATCC 4698, Escherichia coli ATCC 11775, and Salmonella typhimurium ATCC 14128). The fractions were subsequently profiled using High-Performance Thin Layer Chromatography (HPTLC), and the component of active sub-fractions (SF) was identified using Gas ChromatographyMass Spectrometry (GC-MS). Results: Although no antibacterial activity was recorded of the methanolic extracts in all marine sponges samples, the response towards diethyl ether extracts of $X$. exigua was strong. Out of 17 sub-fractions of diethyl ether profiled, three sub-fractions, i.e. 5,13 , and 14 were active. GC-MS identified five compounds in SF 5, four compounds in SF 13, and three compounds in SF 14. Furthermore, SF 13 and SF 14 could inhibit the growth of all bacteria tested, indicating a broad-spectrum activity. On the contrary, SF 5 showed selective inhibition only to $E$. coli and $S$. typhimurium, indicating narrow-spectrum activity. Conclusion: Bioactive SF 13 of $X$. exigua has a high potential as an antibacterial agent but in vitro assessment such as cytotoxicity against mammalian cell lines is needed to determine the toxicity and drug response.

Key words: Diethyl ether, HPTLC, lotrochota baculifera, Minimum Inhibitory Concentration, Xetospongia exigua, X. muta.
\end{abstract}

\section{INTRODUCTION}

As the world evolves, new contagious diseases emerged. To date, the bacterial infection has become an issue of concern to health practitioners requiring an effective intervention strategy to curb the widespread use of antibiotics. ${ }^{1}$ Antibiotic resistance is the biggest challenge in today's global health since the misuse or overuse of antibiotics causes the infections to be much harder to treat. The World Health Organization (WHO) has declared ten species of bacterial strains that can develop into multi-resistant antibiotic strains. They are Streptococcus pneumoniae, Klebsiella pneumoniae, Mycobacterium tuberculosis, Neisseria gonorrhoeae, Staphylococcus aureus, Pseudomonas aeruginosa, Acinetobacter baumannii, Escherichia coli, Enterococcus faecium, and Enterococcus faecalis. $^{2}$

Marine invertebrates are becoming an essential source of novel bioactive compounds for the treatment of infectious diseases. The reasons are due to the long history of evolution, and its molecular diversity is more advanced relative to terrestrial equivalents. ${ }^{3}$ Marine sponges are a type of sessile aquatic invertebrate animal, which belongs to the phylum Porifera. ${ }^{4}$ They have no symmetrical tissues or organs and can be found in various shapes, sizes, and colours. Numerous tiny spores and canals can be found on their bodies that functionally involved in the filter-feeding system. ${ }^{5}$ Most of the sponges that originated from the South China Sea belong to the class Demospongiae. Ten orders were identified in this class; among them are axinellida, hadromerida, holichondria, haplosclerida, and homosclerophoria, with a total of 29 families and more than 121 species. ${ }^{6}$

To date, around 5300 compounds have been successfully isolated from 500 species of sponges.? Each compound has been reported as having antibacterial, anticancer, anti-fungal, antituberculosis, anti-inflammatory, anti-fouling, and anti-malarial properties. ${ }^{8,9}$ Due to its speciesrichness, sponges are regarded as a prolific source of novel steroids, terpenoids, peptides, macrolides, and alkaloids. ${ }^{10}$ Most of these biologically active compounds have unique, unprecedented structures with cyclic or linear peptides containing the unusual amino acid, as compared to compounds from other sources such as terrestrial and microbial systems. ${ }^{11}$ In this study, the bioactive compounds from three marine sponges (X. exigua, X. muta, and I. baculifera) were identified and their antibacterial activity was determined.

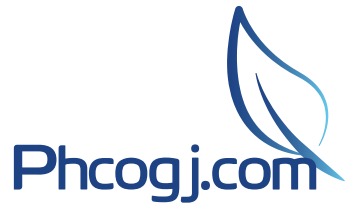

Cite this article: Kamaruding NA, Ismail N, Sokry N. Identification of Antibacterial Activity with Bioactive Compounds from Selected Marine Sponges. Pharmacogn J. 2020;12(3):493-502. 


\section{MATERIALS AND METHODS}

\section{On-site field sampling}

Samples of marine sponges (X. exigua, X. muta, and I. baculifera) were collected from Bidong and Karah Islands in Terengganu by scuba diving at a depth of 8 to $15 \mathrm{~m}$. The details of the collection sites are shown in Table 1. The samples were identified and authenticated taxonomically by experts. After collection, the samples were stored on ice and transported to the laboratory at the Institute of Marine Biotechnology, Universiti Malaysia Terengganu (UMT). Then, the samples were subjected to lyophilisation using a freeze-dryer machine (Labconco, USA) and later ground to obtain the powder.

\section{Preparation of marine sponges extracts}

The lyophilised sample was extracted using the cold maceration technique. ${ }^{12}$ Briefly, $10 \mathrm{~g}$ of each sample of X. exigua, X. muta, and I. baculifera were soaked into absolute methanol at $10 \%(\mathrm{w} / \mathrm{v})$. The soaking step was repeated three to four times at room temperature overnight to maximise the extraction yield. The extracts were filtered out the following day using a Whatman filter paper (No. 2). Next, the supernatant was concentrated using a rotary evaporator (Buchi, USA) to obtain the methanol crude extract.

\section{Separation of crude extracts using solvent partitioning}

Crude extracts of the marine sponges were separated using liquid-liquid extraction by two-phases of organic solvents separation comprising of diethyl ether and butanol, which were chosen based on their polarities, with some modifications. ${ }^{13}$ First, the sample was immersed in diethyl ether. After that, the samples were transferred into the separating funnel. Next, distilled water was added into the diethyl ether extract at a ratio of 1:2. The mixture was shaken vigorously to settle down the compounds. The partitioning process was repeated at least three times until the diethyl ether phase turned colourless. After the separation process was completed, the organic layer consisting of diethyl ether was removed so that the aqueous layer remained for the second separation process using butanol as an organic solvent. After the addition of butanol into the aqueous layer, distilled water was subsequently added to obtain a mixture of polar and non-polar phases. The mixture was shaken vigorously, and the polar and non-polar fractions were concentrated using a rotary evaporator (IKA, Taiwan). The extracts were stored at room temperature until further use for fractionation.

\section{Metabolites profiling using high-performance thin layer chromatography (HPTLC)}

The metabolites constituents of the extracts were profiled using HPTLC, following the method described by Minase and Dole ${ }^{14}$ with some modifications. The HPTLC (Camag, Switzerland) was performed on a pre-coated HPTLC plate of silica gel $60 \mathrm{~F}_{254}$ (Merck, Germany) at $20 \mathrm{~cm} \times 10 \mathrm{~cm}$, with a thickness of $200 \mu \mathrm{m}$. The sub-fractions were reconstituted in methanol at a concentration of $10 \mathrm{mg} / \mathrm{mL}$. Then, the samples were applied on the plate under a mixture of a solvent system consisting of hexane: ethyl acetate at a ratio of 7:3. After running the

Table 1: Description of location of sampling site for selected marine sponges.

\begin{tabular}{ccc}
\hline Sample & Location of Sampling & $\begin{array}{c}\text { Global Positioning } \\
\text { System }\end{array}$ \\
\hline X. exigua & Bidong Island & $\mathrm{N} 05^{\circ} 37.6306^{\prime}$ \\
& & $\mathrm{E} 103^{\circ} 31.7874^{\prime}$ \\
X. muta & Bidong Island & ${\mathrm{N} 04^{\circ} 12.8000^{\prime}}^{\prime}$ \\
& & $\mathrm{E} 100^{\circ} 32.5900^{\prime}$ \\
I. baculifera & Karah Island & $\mathrm{N} 05^{\circ} 35.5000^{\prime}$ \\
& & $\mathrm{E} 103^{\circ} 33.4000^{\prime}$ \\
\hline
\end{tabular}

extracts through the plate using the complete solvent system, the plate was visualised under two different UV wavelengths at $254 \mathrm{~nm}$ and $366 \mathrm{~nm}$ following the method described by Ebada et al. ${ }^{15}$ Both UV wavelengths were selected because they could detect the presence of aromatic rings, conjugated double bonds, and unsaturated compounds. Next, the derivatisation of compounds such as phenols, terpenes, sugars, steroids, amines aldehydes, ketones, or allylic alcohols in the samples was further detected by using p-anisaldehyde-sulphuric acid reagent as a visualising agent.

\section{Identification of compounds by gas chromatography- mass spectrometry (GC-MS)}

The compounds present in the samples were identified using GC-MS (Shimadzu, Japan). The apparatus for GC-MS consisted of a one-fused silica capillary column made up of $100 \%$ dimethyl polysiloxane at the dimension size of $30 \mathrm{~mm}$ (length) $\times 0.25 \mathrm{~mm}$ (diameter) $\times 0.25 \mathrm{~mm}$ (film thickness). Helium gas at $99.9 \%$ saturation was injected at a flowrate of $0.96 \mathrm{~mL} / \mathrm{min}$ to permit electron ionisation energy to occur at 70 $\mathrm{eV}$. The temperatures of the injector and ion sources were maintained at $300{ }^{\circ} \mathrm{C}$. The oven temperature was initially at $40{ }^{\circ} \mathrm{C}$ for $2 \mathrm{~min}$, then increased at a rate of $9{ }^{\circ} \mathrm{C} / \mathrm{min}$ until $300{ }^{\circ} \mathrm{C}$ and held at $300{ }^{\circ} \mathrm{C}$ for 3 min. Mass spectra were recorded within a scan-interval at $0.5 \mathrm{~s}$ and scan range at $50-600 \mathrm{~m} / \mathrm{z}$. The total GC running time was $56 \mathrm{~min}$. The percentage of each component was calculated by comparing its average peak area to the total area following the method described by Anupriya et al. ${ }^{16}$ The similarity index of the major compounds detected were compared with the National of Standards and Technology (NIST), Chemistry Web-book, and Golm Metabolome Database (GMD).

\section{Determination of antibacterial activity using disc diffusion test (DDT)}

The protocol for DDT was performed according to the method described by Laila et al. ${ }^{17}$ with some modifications. Two test strains of Gram-positive bacteria (S. aureus [ATCC 25923] and Micrococcus luteus [ATCC 4698]) and two test strains of Gram-negative bacteria (E. coli [ATCC 11775] and Salmonella typhimurium [ATCC 14128]) were used. All the test strains were obtained from the Microbiology Laboratory, Universiti Malaysia Terengganu. The inoculum of test strains was cultured into the nutrient broth. The solutions were vortexed to form a smooth suspension and subjected to incubation overnight. For the DDT assay, approximately $20 \mathrm{~mL}$ of sterile Mueller Hinton Agar (MHA) was poured into the Petri dishes and allowed to sit at room temperature. Then, the turbidity of the overnight culture of test strains was adjusted to a $0.5 \mathrm{McF}$ arland standard. After adjustment, the test strains were swabbed uniformly on the solidified agar using a cotton swab and allowed to dry for about $10 \mathrm{~min}$. Sterilised discs were then impregnated with samples and carefully placed onto the agar plate by using sterilised forceps. The negative control was prepared using methanol, while ampicillin was used as a positive control. The reference standard for the measurement of inhibition zones was performed according to Chandra et al. ${ }^{18}$

\section{Determination of half inhibitory concentration $\left(\mathrm{IC}_{50}\right)$ using broth microdilution method (BMM)}

The protocol of BMM was performed on a 96-well microtiter plate based on Kannan et al. ${ }^{19}$ with some modifications. Each sample of diethyl ether sub-fractions (SF 5, SF 13, and SF 14) was diluted at the concentrations of $500,250,125$, and $62.5 \mu \mathrm{g} / \mathrm{mL}$ in a microcentrifuge tube. The turbidity of the bacterial suspension was adjusted to $0.5 \mathrm{McFarland}$ standard to produce $1 \times 10^{5} \mathrm{CFU} / \mathrm{mL}$. To start the BMM assay, $50 \mu \mathrm{L}$ Mueller Hinton broth (MHB) containing each bacterial test strains ( $S$. aureus, M. luteus, E. coli, and S. typhimurium) were added into the microtiter plate as control. For the blank, $100 \mu \mathrm{L}$ of MHB was added into the well. 
Meanwhile, for the test samples, $100 \mu \mathrm{L}$ bacterial test strains from each sample (S. aureus, M. luteus, E. coli, and S. typhimurium) were added into the wells containing $100 \mu \mathrm{L}$ of each diethyl ether sub-fractions (SF 5 , SF 13, and SF 14) at the respective concentrations (500, 250, 125, and $62.5 \mu \mathrm{g} / \mathrm{mL}$ ). Next, the microtiter plates were incubated at $37^{\circ} \mathrm{C}$ for $24 \mathrm{hr}$. The bacterial colonies were counted the following day using the GloMax microplate reader (Promega, UK) at the absorbance of $595 \mathrm{~nm}$. The absorbance values were converted into growth inhibition percentage using the formula stated below. Half-maximal inhibitory concentration $\left(\mathrm{IC}_{50}\right)$ was obtained graphically from the dose-response curves.

Inhibition $(\%)=(\mathrm{NC}-\mathrm{T}) / \mathrm{NC} \times 100$

$\mathrm{NC}=$ Negative Control

$\mathrm{T}=$ Sample Test

\section{RESULTS}

\section{Metabolite profiles}

Based on the HPTLC chromatogram, Figure 1(a) demonstrates the visible compounds of $X$. exigua under the short UV wavelength showing ten spots of dark colour at eight different sub-fractions (number 2, 4, 5, 10, 12, 13, 14, and 15). Meanwhile, Figure 1(b), which illustrates the results of the long UV wavelength, shows seven blue spots observed at seven different sub-fractions (number 2, 3, 4, 5, 6, 7, and 9). The mixture of blue and red spots was visible at eight different subfractions, including SF 10, SF 11, SF 12, SF 13, SF 14, SF 15, SF 16, and SF 17. Both short- and long-UV wavelengths can detect the compounds with aromatic rings or conjugated double bonds as well as some unsaturated compounds such as polyphenols. After being derivatised by $\mathrm{p}$-anisaldehyde, as shown in Figure 1(c), the spots are relatively more abundant at all sub-fractions as compared to the number of spots in the short- and long-UV wavelengths, indicating the presence of compounds corresponding to phenols, terpenes, sugars, steroids, allylic alcohols, amines, aldehydes, or ketones.

\section{Composition of identified compounds}

Identification of compounds using GC-MS revealed that only three subfractions were active, consisting of SF 5, SF 13, and SF 14 (Table 2). Five major compounds were identified at SF 5 with the maximum area of the peak recorded by octadecanoic acid butyl ester (5.38\%), 1-eicosanol (2.90\%), bis(2-ethylhexyl) phthalate $(2.51 \%)$, eicosanoic acid-2hydroxyethyl ester (2.32\%), and hexadecanoic acid butyl ester (1.96\%; as shown in Table 2). The highest percentage of compounds present in SF 5 are hexadecanoic acid butyl ester (51.0\%) as compared to octadecanoic acid butyl ester, which is present at the lowest percentage (18.6\%). All three sub-fractions (SF 5, SF 13, and SF 14) showed the presence of bis(2-ethylhexyl) phthalate with the highest percentage in SF 5 at $39.8 \%$, followed by SF 13 (33.1\%), and SF 14 (17.8\%). Octadecanoic acid butyl ester is present only in two sub-fractions (SF 5 and SF 13) at an equal percentage (18.6\%) but is absent in SF 14. As for SF 13, four compounds are present including bis(2-ethylhexyl) phthalate contributing to the major compounds (33.1\%), followed by octadecanoic acid butyl ester (18.6\%), n-hexadecanoic acid (8.5\%), and 2-tert-butyl-4,6-bis(3,5-ditert-butyl-4-hydroxybenzyl)phenol (3.4\%; Table 2). Meanwhile, three compounds were identified in SF 14, with the major component being hexanedioic acid bis(2-ethylhexyl) ester, followed by bis(2-ethylhexyl)

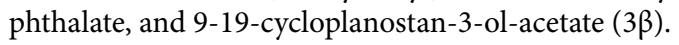

\section{Antibacterial activity of marine sponges extract against ATCC bacteria test strains}

Antibacterial susceptibility test using DDT showed that $X$. exigua moderately inhibited the growth of $S$. aureus and E. coli. However, no activity was observed towards M. luteus and S. typhimurium (Table 3). Two other marine sponges (X. muta and I. baculifera) gave a moderate response only to $M$. luteus but no activity to other test strains (Table 3). All bacterial test strains are strongly inhibited when incubated with the diethyl ether fraction of X. exigua (DEF; Table 4). In contrast, the butanol fraction of $X$. exigua showed a moderate inhibition only to $M$. luteus but not to any other strains. Out of the three active sub-fractions, two sub-fractions (SF 13 and SF 14) of X. exigua gave a positive response to all bacterial strains (S. aureus, M. luteus, E. coli, and S. typhimurium; Table 5). Both SF 13 and SF 14 have strongly inhibited the growth of $M$. luteus and $S$. typhimurium but gave a weak activity against $S$. aureus and E. coli (Table 5). As for SF 5, a strong activity is shown against $S$. typhimurium (Table 5), but the activity of this sub-fraction has weakly inhibited the growth of E. coli. There is no activity detected for SF 5 against $S$. aureus and M. luteus.

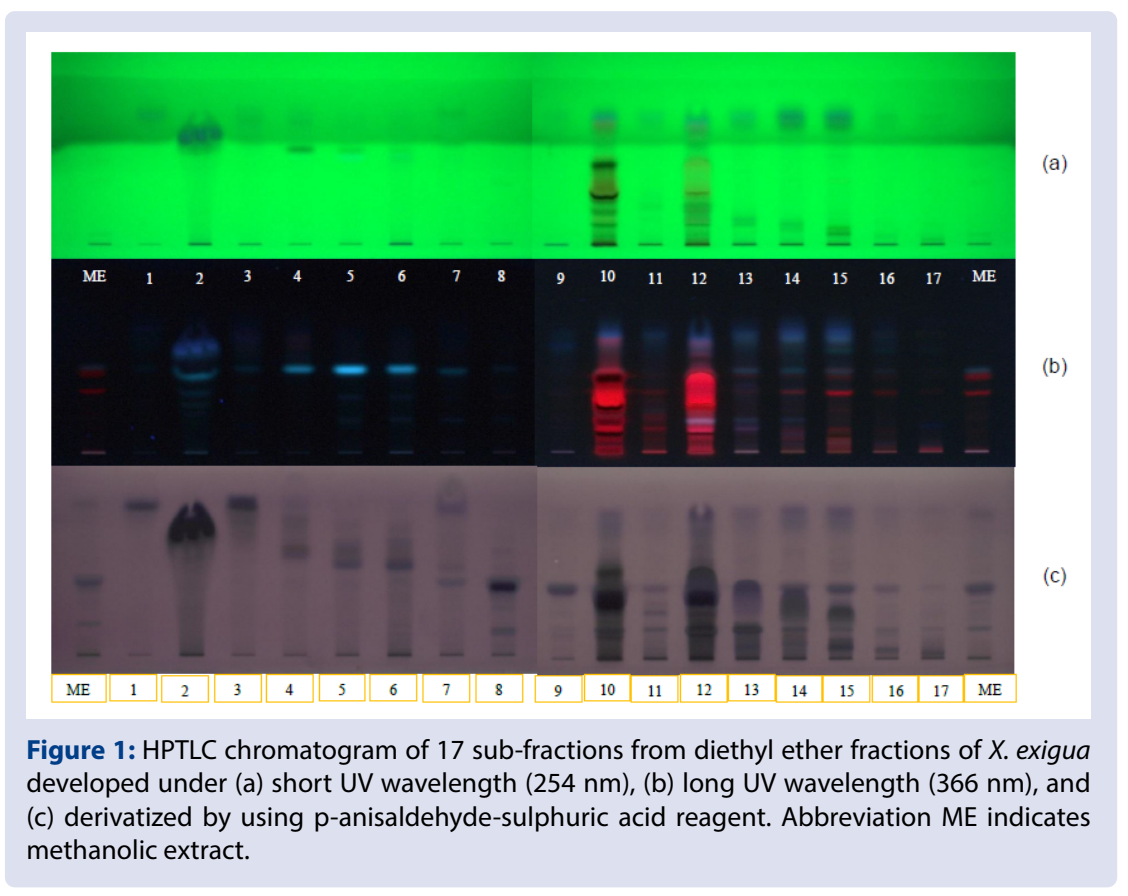


Table 2: Identified components from diethyl ether sub-fractions 5, 13 and 14 of $X$. exigua using GC-MS analysis.

\begin{tabular}{|c|c|c|c|c|c|}
\hline Sub-fraction & Compounds & $\begin{array}{l}\text { Retention Time } \\
\text { (min) }\end{array}$ & $\begin{array}{c}\text { Area } \\
(\%)\end{array}$ & $\begin{array}{l}\text { Height } \\
(\%)\end{array}$ & $\begin{array}{c}\text { Abundance } \\
(\%)\end{array}$ \\
\hline \multirow{5}{*}{5} & 1-eicosanol & 36.72 & 2.90 & 4.59 & 34.4 \\
\hline & Hexadecanoic acid butyl ester & 38.63 & 1.96 & 2.82 & 51.0 \\
\hline & Octadecanoic acid butyl ester & 42.20 & 5.38 & 7.87 & 18.6 \\
\hline & Eicosanoic acid-2-hydroxyethyl ester & 43.14 & 2.32 & 3.33 & 43.1 \\
\hline & Bis(2-ethylhexyl)phtalate & 44.61 & 2.51 & 3.81 & 39.8 \\
\hline \multirow{4}{*}{13} & n-hexadecanoic acid & 34.30 & 11.73 & 9.20 & 8.5 \\
\hline & Octadecanoic acid butyl ester & 42.22 & 5.37 & 8.06 & 18.6 \\
\hline & $\operatorname{Bis}(2$-ethylhexyl)phtalate & 44.61 & 3.03 & 5.59 & 33.1 \\
\hline & 2-tert-butyl-4,6-bis(3,5-di-tert-butyl-4-hydroxybenzyl) phenol & 54.19 & 29.37 & 20.68 & 3.4 \\
\hline \multirow{3}{*}{14} & Hexanedioic acid, bis(2-ethylhexyl) ester & 42.24 & 25.21 & 30.72 & 4.0 \\
\hline & Bis(2-ethylhexyl) phtalate & 44.62 & 5.64 & 7.49 & 17.8 \\
\hline & 9-19-cycloplanostan-3-ol-acetate $(3 \beta)$ & 55.67 & 11.32 & 4.58 & 12.9 \\
\hline
\end{tabular}

Table 3: Antibacterial susceptibility test using DDT for $X$. exigua, X. muta and $I$. baculifera against four bacteria test strains (S. aureus, M. luteus, E. coli and S. typhimurium).

\begin{tabular}{ccccc}
\hline Sample & \multicolumn{4}{c}{ Antibacterial susceptibility test } \\
\cline { 2 - 5 } & S. aureus & M. luteus & E. coli & S. typhimurium \\
\hline X. exigua & $\mathrm{M}$ & - & $\mathrm{M}$ & - \\
X. muta & - & $\mathrm{W}$ & - & - \\
$\begin{array}{c}\text { L. baculifera } \\
\text { Positive control } \\
\text { (Ampicillin) }\end{array}$ & - & $\mathrm{W}$ & $\mathrm{M}$ & $\mathrm{M}$ \\
Negative control & $\mathrm{M}$ & $\mathrm{S}$ & - & - \\
(Methanol) & - & - & & \\
\hline
\end{tabular}

${ }^{*}$ Degree of inhibition zones was measured in reference to Chandra et al. ${ }^{[1]}$

$\{$ W: weak activity (6-9 mm), M: moderate activity $(10-15 \mathrm{~mm})$, S: strong activity ( $\geq 16 \mathrm{~mm})$, “- “: No activity\}.

Table 4: Antibacterial susceptibility test using DDT for diethyl ether fraction (DEF) and butanol fraction (BUF) of X. exigua against four bacteria test strains (S. aureus, M. Iuteus, E. coli and S. typhimurium).

\begin{tabular}{ccccc}
\hline \multirow{2}{*}{ Sample } & \multicolumn{4}{c}{ Antibacterial susceptibility test } \\
\cline { 2 - 5 } & S. aureus & M. luteus & E. coli & S. typhimurium \\
\hline DEF & S & S & S & S \\
BUF & - & M & - & - \\
$\begin{array}{c}\text { Positive control } \\
\text { (Ampicillin) }\end{array}$ & S & S & S & S \\
$\begin{array}{c}\text { Negative control } \\
\text { (Methanol) }\end{array}$ & - & - & - & - \\
\hline
\end{tabular}

${ }^{*}$ Degree of inhibition zones was measured in reference to Chandra et al. ${ }^{[21]}$

\{W: weak activity (6-9 mm), M: moderate activity $(10-15 \mathrm{~mm})$, S: strong activity ( $\geq 16 \mathrm{~mm}),{ }^{-}{ }^{-}$: No activity\}.

Table 5: Antibacterial susceptibility test using DDT for diethyl ether sub-fractions 5, 13 and 14 of $X$. exigua against four bacteria test strains (S. aureus, M. luteus, E. coli and S. typhimurium).

\begin{tabular}{ccccc}
\hline Sample & \multicolumn{4}{c}{ Antibacterial susceptibility test } \\
\cline { 2 - 5 } & S. aureus & M. luteus & E. coli & S. typhimurium \\
\hline Sub-fraction 5 & - & - & W & S \\
Sub-fraction 13 & W & S & W & S \\
Sub-fraction 14 & W & S & M & S \\
$\begin{array}{c}\text { Positive control } \\
\text { (Ampicillin) }\end{array}$ & M & S & & S \\
Negative control & & & - & - \\
(Methanol) & - & - &
\end{tabular}

${ }^{*}$ Degree of inhibition zones was measured in reference to Chandra et al. ${ }^{[21]}$

\{W: weak activity (6-9 mm), M: moderate activity (10-15 mm), S: strong activity ( $\geq 16 \mathrm{~mm})$, “- “: No activity\}. 


\section{Half maximal inhibitory concentration $\left(\mathrm{IC}_{50}\right)$}

The minimal concentration of diethyl ether SF 5 of $X$. exigua $(62.5$ $\mu \mathrm{g} / \mathrm{mL}$ ) managed to inhibit the growth of $M$. luteus at the highest percentage (18\%) as compared to other strains of bacteria (S. aureus, E. coli, and S. typhimurium), which are only inhibited at $7 \%, 13 \%$, and $14 \%$, respectively (Figure $2 \mathrm{a}$ ). Although a two-fold concentration increase of diethyl ether SF $5(125 \mu \mathrm{g} / \mathrm{mL})$ inhibited three strains of bacteria (M. luteus, E. coli, and S. typhimurium) at $20 \%-30 \%$ inhibitions, it minimally inhibited $S$. aureus (Figure 2a). Moreover, the detection of a high percentage (70\%-75\%) of S. typhimurium inhibition is in parallel with the increasing concentration of diethyl ether of SF 5. The concentration of this fraction is between $250 \mu \mathrm{g} / \mathrm{mL}$ to $500 \mu \mathrm{g} /$ $\mathrm{mL}$ (Figure 2a), surpassing other bacterial strains growth inhibition $(S$. aureus: $30 \%$ to $45 \%$, M. luteus: $45 \%$ to $59 \%$, and E. coli: $60 \%$ to $72 \%$ ). Both diethyl ether of SF 13 and SF 14 showed the highest antibacterial activity (97\% and $92 \%$, respectively) against M. luteus at $500 \mu \mathrm{g} / \mathrm{mL}$ (Figure $2 \mathrm{~b}$ and $2 \mathrm{c}$ ). However, at the low concentration of $62.5 \mu \mathrm{g} / \mathrm{mL}$, both sub-fractions of SF 13 and SF 14 gave inhibition at $60 \%$ and $57 \%$, respectively (Figure $2 \mathrm{~b}$ and $2 \mathrm{c}$ ). Similarly, the degree of inhibition increased by the increased concentrations of diethyl ether of SF 13 and SF $14(62.5 \mu \mathrm{g} / \mathrm{mL}$ to $500 \mu \mathrm{g} / \mathrm{mL})$ in other bacterial strains such as $S$. aureus, E. coli, and S. typhimurium. Among the three sub-fractions, diethyl ether of SF 13 showed the best potency with the lowest values of $\mathrm{IC}_{50}$ to inhibit the growth of $S$. aureus, M. luteus, and S. typhimurium (561.2 $\pm 11.2,41.7 \pm 2.5$ and 106.3 \pm 4.2 , respectively; Figure 3). However, for $E$. coli, the diethyl ether of SF 14 produced the best potency,

(a)

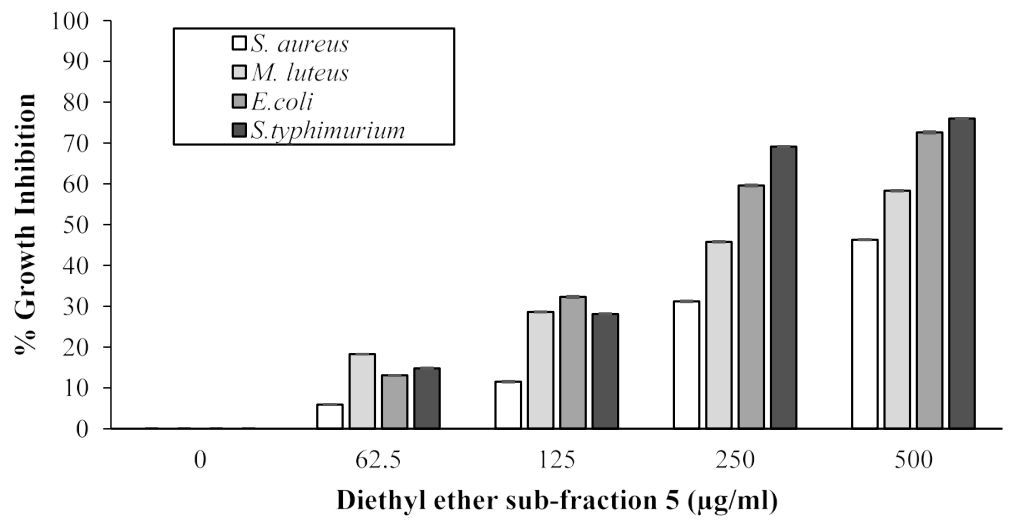

(b)

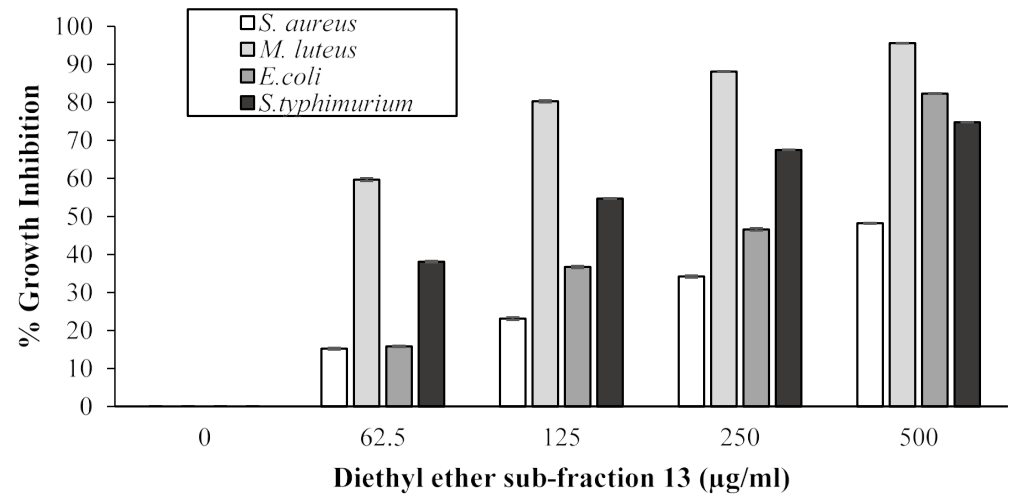

(c)

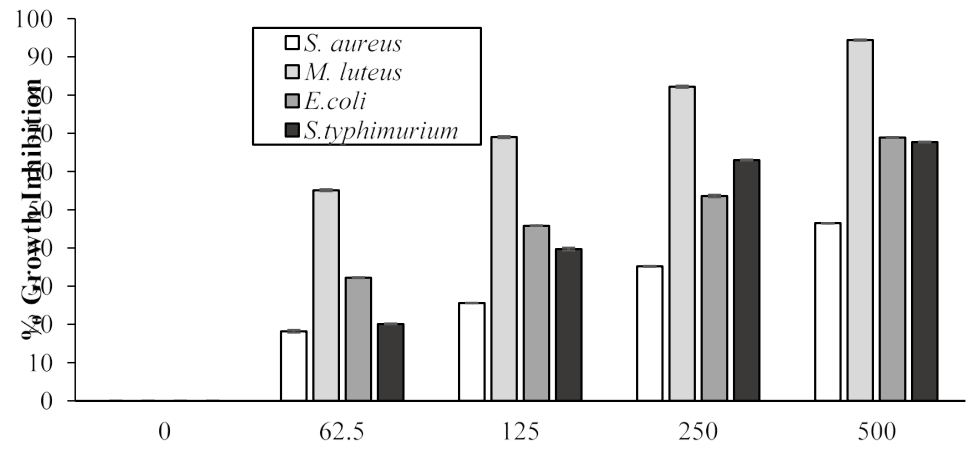

Diethyl ether sub-fraction $14(\mu \mathrm{g} / \mathrm{ml})$

Figure 2: Antibacterial activity of diethyl ether sub-fraction 5 (a), sub-fraction 13 (b) and sub-fraction 14 (c) of X. exigua at various concentrations using broth microdilution method challenged by four different bacterial test strains (S. aureus, M. luteus, E. coli, and S. typhimurium). Percentage of growth inhibition was expressed as mean \pm S.D. 


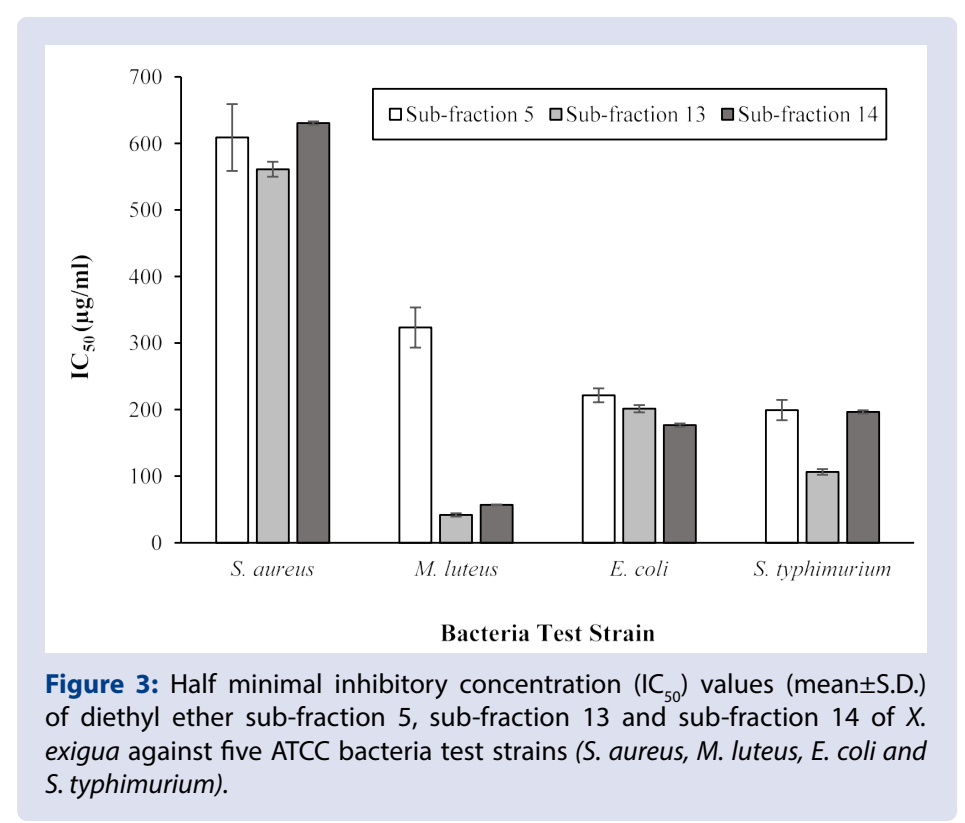

recorded by the lowest $\mathrm{IC}_{50}$ value at $176.7 \pm 2.4$ (Figure 3). In contrast, the diethyl ether of SF 5 produced the lowest potency against $M$. luteus $\left(\mathrm{IC}_{50}=323.4 \pm 30.2\right)$, E. coli $\left(\mathrm{IC}_{50}=221.5 \pm 10.5\right)$, and S. typhimurium $\left(\mathrm{IC}_{50}\right.$ $=199.3 \pm 15.2)$ than the diethyl ether of SF 13 and SF 14 .

\section{DISCUSSION}

Marine sponges are known to possess many bioactive compounds, which are of critical importance for the development of new antibacterial drugs. ${ }^{20-25}$ In this study, we screened antibacterial activity from methanolic extracts of three samples of marine sponges $(X$. exigua, X. muta, and I. baculifera). Results showed that only the extracts of $X$. exigua gave a moderate activity towards $S$. aureus and E. coli tested but not towards X. muta and I. baculifera. Both samples exhibited weak activity against $M$. luteus. The preliminary screening indicated that $X$. exigua has a broad-specificity against Gram-negative and -positive bacteria, but narrow-specificity only to Gram-positive bacteria for $X$. muta and I. baculifera. According to Qaralleh et al. ${ }^{26}$ differences in the chemical concentration and composition among the species might be the contributing factors to the full range variation of the antibacterial activity. In their findings, Qaralleh et al. ${ }^{26}$ found that methanol extracts of $X$. exigua gave an antibacterial activity against $S$. aureus, Bacillus cereus, and E. coli with the diameter of inhibition of $9.5,9.5$, and 7.5 $\mathrm{mm}$, respectively.

In the present study, the organic extracts of methanol are hydrophobic with non-polar properties; thus, displaying antibacterial activity. Whereas the aqueous extract of water consisting of hydrophilic with polar properties displayed no antibacterial activity. Methanol is preferred as an organic solvent to extract multi-variable types of hydrophobic compounds because it can extract both non-polar and polar compounds, as well as proteins. ${ }^{27}$ This finding was in agreement with Touti et al. ${ }^{28}$ who found very weak antibacterial activity in the aqueous extract (water) from seven Tunisian marine sponges compared to the organic phase of ethyl acetate extracts. Another report by Ankisetty and Slattery ${ }^{29}$ suggested that the mixture of dichloromethane/ methanol $(1: 1 \mathrm{v} / \mathrm{v})$ to extract Xetospongia sp. displayed a satisfactory result of antibacterial activity against both Gram-negative bacteria $(P$. aeruginosa) and Gram-positive bacteria (Mycobacterium intracellulare) with $\mathrm{IC}_{50}$ values of 2.07 and $1.03 \mu \mathrm{g} / \mathrm{mL}$, respectively. The present study also found that the compound extracted from $X$. exigua using diethyl ether, which was classified as the non-polar solvent, gave better antibacterial activity than the polar phase of butanol extract suggesting that the natural existence of non-polar compounds exhibiting antibacterial properties. Hence, this finding strongly refuted the theory of polar compounds displaying antibacterial properties.

Based on the GC-MS analysis, all diethyl ether sub-fractions of $X$. exigua, namely SF 5, SF 13, and SF 14 showed the abundance of bis(2ethylhexyl) phthalate (BEP). The potent inhibitory activity against $S$. typhimurium in all diethyl ether sub-fractions 5, 13, and 14 provided suggestive evidence of the potential of BEP as an antibacterial agent in killing Gram-negative bacteria. Several scientific evidence supports the finding that BEP isolated from marine-derived sponges and microorganisms acts as a potent antimicrobial agent. ${ }^{30-33}$ Chemical profiling using marine-derived actinobacteria, Nocardiopsis sp. SCA21, as reported by Siddharth and Ravi ${ }^{32}$ found that BEP showed a broadspectrum inhibitory activity against MRSA (ATCC NR-46171), MRSA (ATCC 46071), K. pneumoniae (ATCC 13883), Bacillus subtilis (ATCC 6633), and S. aureus (ATCC 12600) with MIC values in the range of $7.81-250 \mu \mathrm{g} / \mathrm{mL}$. Moreover, Rajivgandhi et al. ${ }^{33}$ observed BEP-treated colistin-resistant extract on P. aeruginos $a$ and $K$. pneumoniae resulted in the occurrence of the irregular shape of membrane morphology and caused the death of both bacterial strains. Hence, this study can provide an insight on BEP as a biocontrol agent in the treatment of Methicillinresistant Staphylococcus aureus (MRSA) that is rampantly occurring in hospital patients worldwide.

Besides their potential as an antibacterial agent, the drawback of phthalate derivatives is that they have been widely used as a source of plasticiser. The US Environmental Protection Agency (US EPA) ${ }^{34}$ has listed six phthalate plasticisers as priority marine pollutants such as dimethyl phthalate (DMP), diethyl phthalate (DEP), dibutyl phthalate (DBP), benzyl butyl phthalate (BBP), diethylhexyl phthalate (DEHP), and dioctyl phthalate (DnOP). The lethal effect of phthalate derivatives has resulted in the reduction of phytoplankton biomass community, as well as causing the structural changes and decrease of Chl-a concentration at $50 \% .{ }^{35}$ The DEHP is the most common carcinogenic compounds that may impair neurodevelopment, respiratory, and reproductive systems upon dispersal in the environment. For instance, low birth-weight and retarded growth and development of the placenta occurred in rats treated with DEHP at $125 \mathrm{mg} / \mathrm{kg} / \mathrm{day}{ }^{36}$ Furthermore, the DEHP has been known as a potent compound to trigger a metabolic dysfunction by inhibiting the liver function, glucose absorption, aromatase activity, the expression of insulin receptor, GLUT4 
proteins, growth of follicle, increasing the gonadotropin serum level at high dose $(30 \mathrm{mg} / \mathrm{kg}$ be/day), and promoting lipid accumulation in hepatocytes. ${ }^{37-39}$

Hexadecanoic acid is one type of straight-chain saturated fatty acid, which is commonly found in plants and animals. According to $\mathrm{Pu}$ et $a l .{ }^{40}$ the hexadecanoic acid and its derivatives from neem oil could inhibit the growth of $S$. aureus, E. coli, and Salmonella sp. with the MIC within the range of 20 to $0.625 \mathrm{mg} / \mathrm{mL}$. Our study indicated that hexadecanoic acid constitutes one of the most abundant isolated compounds from $X$. exigua. Our screening results coincided with Parsons et al. ${ }^{41}$ who found that brown algae, Cytosoria compressa and marine sponge, Spongia officinalis extracts contained fatty acids such as hexadecanoic and octadecanoic acids as the primary component, which play a vital role as anionic surfactants under low $\mathrm{pH}$ targeting the disruption of bacterial cell wall and membranes. ${ }^{42}$

From the previous findings, we determined that the $\mathrm{IC}_{50}$ value for all diethyl ether sub-fractions of $X$. exigua suggested that the Grampositive bacteria were more sensitive than Gram-negative bacteria. These findings were in agreement with many documented studies on the antibacterial property of sponges that showed Gram-positive bacteria are more susceptible to marine sponges extracts as compared to Gram-negative. ${ }^{43,44}$ The reasons are possibly due to the biochemical composition of the outer membrane of the Gram-negative bacteria consisting of lipoprotein and lipopolysaccharide, which are selectively permeable and resistant, thereby modulates the uptake of antimicrobial compounds. ${ }^{45}$

To the best of our knowledge, this study is believed to be the first report on the identification of bioactive compounds potentiating antibacterial properties from the sub-fraction of HPTLC of $X$. exigua. One of the limitations of this study is that the antibacterial activity of the $X$. exigua was performed on only four pathogens. Therefore, future study is recommended to expand more pathogens with a particular focus on life-threatening diseases such as HIV, malaria, and endemic cases of MRSA.

\section{CONCLUSION}

Three sub-fractions of diethyl ether (SF 5 , SF 13, and SF 14) of $X$. exigua actively exhibited antibacterial activity. SF 5 consisted of five compounds, namely 1-eicosanol, hexadecanoic acid butyl ester, octadecanoic acid butyl ester, eicosanoic acid-2-hydroxyethyl ester, and bis(2-ethylhexyl) phthalate, while SF 13 consisted of four compounds, namely n-hexadecanoic acid, octadecanoic acid butyl ester, bis(2ethylhexyl)phthalate and 2-tert-butyl-4,6-bis(3,5-di-tert-butyl-4hydroxybenzyl)phenol. The final sub-fraction, SF 14, consisted of three compounds, namely hexanedioic acid, bis(2-ethylhexyl)ester, bis(2ethylhexyl) phthalate, and 9-19-cycloplanostan-3-ol-acetate (3ß). SF 13 and SF 14 could inhibit the growth of all bacteria tested, indicating a broad-spectrum activity, but SF 5 showed selective inhibition only towards E. coli and S. typhimurium.

\section{CONFLICTS OF INTEREST}

None.

\section{ACKNOWLEDGEMENT}

We appreciate the use of equipment and facilities for this study, which was provided by the Institute of Marine Biotechnology, Universiti Malaysia Terengganu. We would like to express our heartfelt gratitude to those who were involved in this study directly or indirectly.

\section{ABBREVIATIONS}

BEP: bis(2-ethylhexyl) phthalate, BMM: Broth Microdilution Method, BUF: Butanol fraction, DDT: Disc Diffusion Test, DEF: Diethyl ether fraction, GC-MS: Gas Chromatography-Mass Spectrometry, $\mathrm{IC}_{50}$ : Half Maximal Inhibitory Concentration, GMD: Golm Metabolome Database, HPTLC: High-Performance Thin Layer Chromatography, MHB: Mueller Hinton broth, MIC: Minimum Inhibitory Concentration, MRSA: Methicillin Resistant Staphylococcus aureus, NIST: National of Standards and Technology.

\section{REFERENCES}

1. Zaman $S$, Hussain MA, Nye R, Mehta V. A review on antibiotic resistance: alarm bell is ringing. Cureus. 2017;9(6):1-9

2. Ventola $\mathrm{CL}$. The antibiotic resistance crisis part 1: causes and threats. $P \& T$. 2015;40(4):277-83

3. Bertrand B, Munoz-Garay C. Marine antimicrobial peptides: A promising source of new generation antibiotics and other bioactive molecules. International Journal of Peptide Research and Therapeutics. 2018.

4. Ramel G. Phylum Porifera. Available from:

5. http://www.earthlife.net/inverts/porifera.html/

6. Hickman CP, Roberts LS, Keen SL, Larson A, Eisenhour DJ. Animal diversity, 5th Edition. McGraw Hill International Edition, New York; 2009.

7. Zhang W, Guo Y-W, Gu Y. Secondary metabolites from the South China Sea invertebrates:

8. chemistry and biological activity. Current Medicinal Chemistry. 2006;13:2041 90.

9. Anjum K, Abbas SQ, Shah SAA, Akhter N, Batool S, Hassan SS. Marine sponges as a drug treasure. Biomolecules and Therapeutics. 2016;24(4):347-62.

10. Mioso R, Marante FJT, Bezerra RDS. Cytotoxic compounds derived from marine sponges. A review (2010-2012). Molecules. 2017;22(208):1-34

11. He F, Mai LH, Garderes J. Major antimicrobial representatives from marine sponges and/or their associated bacteria. In: Muller WEG et al. eds. Blue Biotechnology, Progress in Molecular and Subcellular Biology. Springer International Publishing; 2017;35-89.

12. Andersen RJ, Van Soesp RWMV, Kong FM. Alkylpiperidine alkaloids isolated from marine sponges in the order haplosclerida. Alkaloids: Chemical and Biological Perspective. 1996;10:301-35

13. Abel A, Anoland G. Bioactive peptides from marine sources: pharmacological properties and isolation procedures. Journal of Chromatography B. 2004;803:4153.

14. Parekh J, Chanda SV. In vitro antimicrobial activity and phytochemical analysis of some Indian medicinal plants. Turkish Journal of Biology. 2007;31:53-8.

15. Putz A. Secondary metabolites from marine sponges, with focus on the chemical ecology and biochemical characterization of the stress-induced biotransformation of Aplysina alkaloids. 2009; PhD Dissertation. Institute of Pharmaceutical Biology and Biotechnology, Germany.

16. Minase AS, Dole MN. Development and validation of analytical method for simultaneous of Cilnidipine and Olmesartan Medoxomil in bulk and tablet dosage form by HPTLC. Journal of Advanced Scientific Research. 2014;5(3):34 8.

17. Ebada SS, Edrada RA, Lin W. Methods for isolation, purification and structura elucidation of bioactive secondary metabolites from marine invertebrates. Nature Protocols. 2008:3(12):1820-31

18. Anupriya S, Elangovan K, Murugesan K. Multiple screening of phytochemicals from different plant extracts of Spermacoce hispida L. by GC-MS method. International Journal of Pharmaceutical Development and Technology. 2016;6(2):71-9

19. Laila A, Mwangi C, Uku J. Antimicrobial activity of various extracts of the sea urchin Tripneustes gratilla (Echinoidea). African Journal of Pharmacology and Therapeutics. 2012;1(1):19-23.

20. Chandra R, Dwivedi V, Shivam K. Detection of antimicrobial activity of Oscimum sanctum (Tulsi) and Trigonella foenum (Methi) against some selected bacterial and fungal strains. Research Journal of Pharmaceutical, Biological and Chemical Sciences. 2011;2(4):809-12.

21. Kannan S, Ramdevi SR, Hopper W. Efficacy of methanolic extract of a marine ascidian, Lissoclinum bistratum for antimicrobial activity. Journal of Chemical, Biological and Physical Sciences. 2009;5(4):4119-25.

22. Ren S, Ma W, Xu T. Two novel alkaloids from the South China Sea marine sponge Dysidea sp. The Journal of Antibiotics. 2010;63:669-701.

23. Youssef DTA, Badr JM, Shaala LA. Ehrenasterol and biemnic acid: new bioactive compounds from the Red Sea sponge Biemna ehrenbergi. Phytochemistry Letter. 2015;12:296-301.

24. Youssef DTA, Shaala LA, Alshali KZ. Bioactive Hydantoin alkaloids from the Red Sea marine sponge Hemimycale arabica. Marine Drugs. 2015;13:6609-19.

25. Garcia-Vilas JA, Martinez-Poveda B, Quesada AR. Aeroplysinin-1, a spongederived multi-targeted bioactive marine drug. Marine Drugs. 2016;14(1):1-12. 
26. Ki D-W, Awouafack MD, Wong CP. Brominated diphenyl ethers including a new tribromoiododiphenyl ether from the Vietnamese marine sponge Arenosclera $\mathrm{sp}$. And their antibacterial activities. Chemistry and Biodiversity. 2019.

27. Balansa W, Mettal U, Wuisan ZG. A new Sesquiterpenoid Aminoquinone from an Indonesian marine sponge. Marine Drugs. 2019;17(158):1-7.

28. Qaralleh H, Idid S, Saad S. Antifungal and antibacterial activities of four Malaysian sponge species (Petrosiidae). Journal de Mycologie Medicale. 2010;20:315-20.

29. Prabhu K, Bragadeeswaran S. Biological properties of brittle star Ophiocnemis marmorata collected from Parangupettai, southeast coast of India. Journal of Microbiology. 2013;5(10):110-8.

30. Touati I, Chaieb K, Bakhrouf A. Screening of antimicrobial activity of marine sponge extracts collected from Tunisian coast. Journal de Mycologie Medicale. 2007; 17:183-7.

31. Ankisetty S, Slattery M. Antibacterial secondary metabolites from the cave sponge Xetospongiae sp. Marine Drugs. 2012;10:1037-43

32. Kalinovskaya NI, Romanenko LA, Kalinovsky Al. Antibacterial low-molecular weight compounds produced by the marine bacterium Rhemheimera japonica KMM 9513'. Antonie Van Leeuwenhoek. 2017;110(5):719-26.

33. Beeso R, Bhagooli R, Neergheen-Bhujun VS. Antibacterial activities of tropical marine sponge extracts. Comparative Biochemistry and Physiology. 2017;196:81-90.

34. Siddharth S, Rai VR. Isolation and characterization of bioactive compounds with antibacterial, antioxidant and enzyme inhibitory activities from marinederived rare actinobacteria, Nocardiopsis sp. SCA21. Microbial Pathogenesis. 2019;137(103775):1-13

35. Rajivgandhi G, Muneeswaran T, Maruthupandy M. Antibacterial and anticancer potential of marine endophytic actinomycetes Streptomyces coeruleorubidus GRG4 (KY 457708) compound against colistin resistant uropathogens and A549 lung cancer cells. Microbial Pathogenesis. 2018;125:325-35.

36. United States Environmental Protection Agency (USEPA). Phthalates action plan. Washington, DC: U.S. EPA. 2012; http://www.epa.gov/oppt/existingchemicals/ pubs/actionplans/phthalates_actionplan_revised_2012-03-14.pdf.
37. M'RABET C, Yahia OKD, Couet D. Consequences of contaminant mixture of bisphenol A (BPA) and di-(2-ethylhexyl) Phthalate (DEHP), two plastic-derived chemicals on the diversity of coastal phytoplankton. Marine Pollution Bulletin. 2019:138:385-96.

38. Zong T, Lai LD, Hu J. Maternal exposure to di-(2-ethylhexyl) phthalate disrupts placental growth and development in pregnant mice. Journal of Hazard Material. 2015;297:25-33.

39. Carbone S, Samaniego YA, Cutrera R. Different effects by sex on hypothalamicpituitary axis of prepubertal offspring rats produced by in utero and lactational exposure to di-(2-ethylhexyl) phthalate (DEHP). Neurotoxicology. 2012;33(1):78-84

40. Zhang W, Shen XY, Zhang WW. The effects of di 2-ethyl hexyl phthalate (DEHP) on cellular lipid accumulation in HepG2 cells and its potential mechanisms in the molecular level. Toxicology Mechanisms and Methods. 2017;27(4):245-52.

41. Andrade AJM, Grande SW, Talsness CE. A dose-response study following in utero, and lactational exposure to di-(2-ethylhexyl) phthalate (DEHP): Nonmonotonic dose-response and low dose effects on rat brain aromatase activity. Toxicology. 2006;227(3):185-92.

42. $\mathrm{Pu} Z \mathrm{ZH}$, Zhong $\mathrm{YQ}$, Yin ZQ. Antibacterial activity of 9-octadecanoic acid hexadecanoic acid-Tetrahydrofuran-3,4-diylester from Neem oil. Agricultural Sciences in China. 2010;9(8):1236-40.

43. Parsons JB, Yao J, Frank MW. Membrane disruption by antimicrobial fatty acids releases low-molecular weight proteins from Staphylococcus aureus. Journal of Bacteriology. 2012;194(19):5294-304.

44. Abou-Elela G, Abd-Elnaby H, Ibrahim HAH. Marine natural products and thei potential applications as anti-infective agents. World Applied Sciences Journal 2009;7(7):872-80.

45. Gupta P, Sharma U, SchulzTC. Bicyclic C21 terpenoids from the marine sponge Clathria compressa. Journal of Natural Products. 2012;75:1223-7.

46. Nazemi M, Salimi MA, Salimi PA. Antifungal and antibacterial activity of Haliclona sp. from the Persian Gulf Iran. Journal de Mycologie Medicale. 2014;24:220-4.

47. Tankeo SB, Tane P, Kuete V. In vitro antibacterial and antibiotic-potentiation activities of the methanol extracts from Beilschmiedia acuta, Clusena alisata Newbouldia laevis and Polyscia fulva against multi-drug resistant Gram-negative bacteria. BMC Complementary and Alternative Medicine. 2015;15(412):1-10. 


\section{GRAPHICAL ABSTRACT}

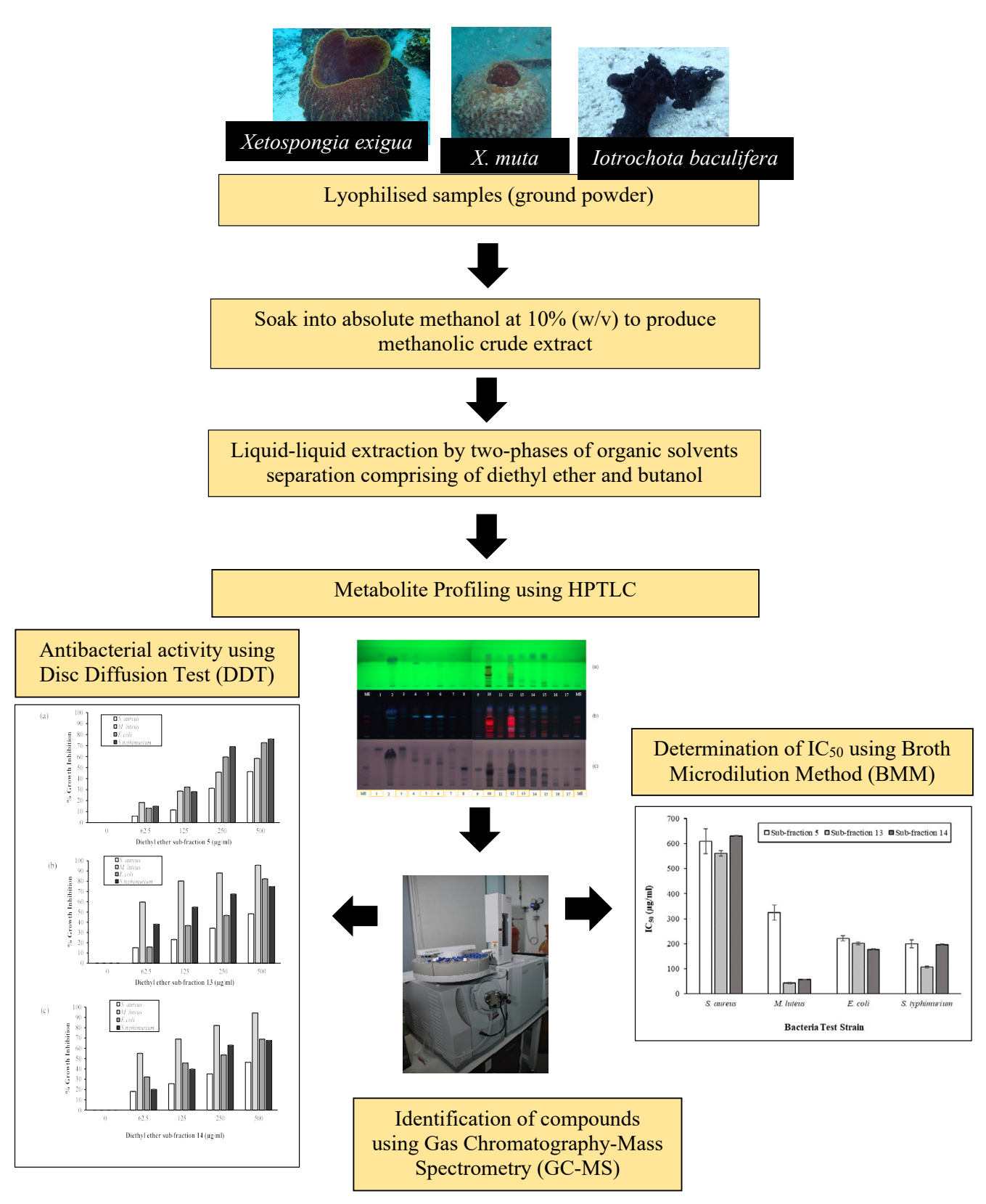

\section{SUMMARY}

- In this study, the antibacterial potential of three selected marine sponges (Xetospongia exigua, X. muta, and I. baculifera) was evaluated using DDT and BMM methods.

- The bioactive constituents of the marine sponges were profiled and identified using HPTLC and GC-MS.

- Out of the three marine sponges samples studied, only the diethyl ether fractions of $X$. exigua possessed a strong antibacterial response, but no activity towards methanol fractions.

- SF 13 and SF 14 of $X$. exigua could inhibit the growth of all bacteria tested, indicating a broad-spectrum activity. However, SF 5 showed selective inhibition only towards E. coli and S. typhimurium, indicating a narrow-spectrum activity. 


\section{ABOUT AUTHORS}

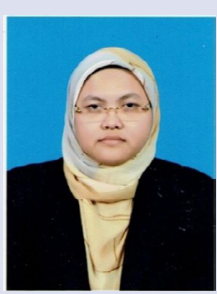

Noor Azlina Kamaruding, Ph.D. post-doctoral researcher at Institute of Marine Biotechnology, Universiti Malaysia Terengganu. Currently, she is working on development and validation of Tachypleus Amoebocyte Lysate (TAL), horseshoe crabs' blood cells that highly sensitive to endotoxin for application as biosensor in biopharmaceutical and food industries. Her research interests focus on understanding metabolic requirements, nutrient dynamics, digestive characteristics during moulting and stress of arthropods (horseshoe crab and crustacean), profiling and characterization of proteins responsible for haemolymph coagulation of arthropods and exploring the recent molecular diagnostic test for endotoxin detection.

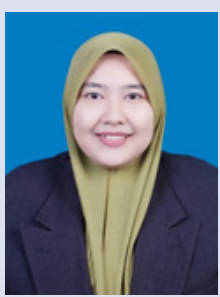

Noormaizura Sokry, M.Sc. was a researcher at Institute of Marine Biotechnology, Universiti Malaysia Terengganu. Her master's degree research entitled was "Identification of Bioactive Compounds with Antibacterial Property from Marine Sponges". Her research interests focus on identifying of bioactive compounds by fractionating the active fraction using column chromatography and tested the active fractions for their antibacterial property by DDT, BMM and metabolites profiling using HPTLC.

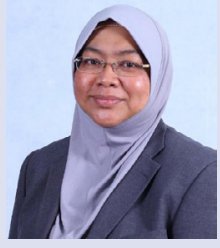

Noraznawati Ismail, Ph.D. Associate professor at the Institute of Marine Biotechnology, Universiti Malaysia Terengganu. Currently, she is head of marine microbes' research division. Her recent research interest is on marine biotechnology focuses on the discovery of potential bioactive metabolites in marine organisms particularly in marine microbes, sponges and horseshoe crabs. This includes exploring for potential microbes associated with marine organisms and functional protein from haemolymph plasma of horseshoe crabs particularly involve in coagulation factors.

Cite this article: Kamaruding NA, Ismail N, Sokry N. Identification of Antibacterial Activity with Bioactive Compounds from Selected Marine Sponges. Pharmacogn J. 2020;12(3):493-502. 